\title{
A Revised Initiation Mechanism for the Radiation Initiated Polymerization of Styrene in Wax
}

\author{
Austin C. Thomas and Tjaart A. Du Plessis \\ Chemistry Division, Atomic Energy Board, Private Bag X256, \\ Pretoria, Republic of South Africa. \\ (Received December 20, 1973)

\begin{abstract}
KEY WORDS $\quad \gamma$-Radiation / Styrene / Paraffin Wax / Radiation Polymerization / Initiation Mechanism /
\end{abstract}

In a former publication ${ }^{1}$ describing the accelerated polymerization rate of styrene by irradiation in the presence of paraffin wax, the chain-transfer reaction (A), in which wax radicals produced by radiolysis of the wax initiate styrene homopolymerization, was proposed to account for the increased initiation rate in the system.

$$
\begin{aligned}
& \mathrm{W} \cdot+\mathrm{S} \longrightarrow \mathrm{W}+\mathrm{S} . \\
& \mathrm{W} \cdot+\mathrm{S} \longrightarrow \mathrm{W}-\mathrm{S} .
\end{aligned}
$$

The alternative reaction (B) was rejected since no grafting of styrene to wax was detected. On reflection, however, this reasoning is in conflict with thermodynamic considerations, since the activation energy for addition of a free radical to a vinyl group $(\sim 7 \mathrm{kcal} / \mathrm{mol})^{2}$ is small compared to that for the abstraction of a hydrogen atom from styrene $(\sim 100 \mathrm{kcal} / \mathrm{mol})^{3}$ as would be required by reaction (A).

ESR measurements on wax and wax/styrene samples irradiated at $-196^{\circ} \mathrm{C}$ were made as the temperature of the samples was slowly increased, in an attempt to detect a change in the spectrum of the mixture due to reaction (B), i.e., change from wax to styryl radicals. Identical spectra were obtained but no change in the character of the spectrum of the mixture was observed, although a more rapid radical decay occurred in the mixture as compared to that in the wax alone, supporting the proposed interaction of styrene with radicals formed initially in the wax. The inability to detect styryl radicals in polymerization reactions by ESR has been reported previously, ${ }^{4,5}$ and is attributed to the rate of the termination reaction being too rapid to allow a measurable concentration of radicals to build up.

In another experiment, pellets of polyethylene $(1.5 \mathrm{~g})$ which may be considered as structurally identical to wax but which exhibits a higher degree of polymerization, were irradiated to 1.5 $\mathrm{Mrad}$ in vacuo at $-196^{\circ} \mathrm{C}$. Styrene monomer $(8 \mathrm{~g})$ was distilled onto the polyethylene and the reactants allowed to warm slowly. Upon opening the ampoules, and after separation of the pellets, the remaining monomer was poured into excess methanol to precipitate any homopolymer formed by the chain-transfer reaction (A). The polyethylene was found to have grafted 300-\% polystyrene (which could not be removed by refluxing with methylene chloride) as compared with $0.3-\%$ homopolymer, showing that the probability of the grafting reaction (B) is about 1000 times greater than that of the chain-transfer reaction (A).

It would seem a logical deduction that a similar situation exists in the wax/styrene system and that the apparent lack of grafting is merely due to the inability to detect low-molecular-weight wax $\left(M_{n} \sim 300\right)$ in the presence of the polystyrene $\left(M_{n} \sim 10^{6}\right)$. The revised reaction scheme should therefore be written:

$$
\begin{aligned}
\mathrm{W} & \rightarrow \mathrm{W} \cdot \\
\mathrm{W} \cdot+\mathrm{S} & \longrightarrow \mathrm{W}-\mathrm{S} . \\
\mathrm{W}-\mathrm{S} \cdot+n \mathrm{~S} & \longrightarrow \mathrm{W}-(\mathbf{S})_{n}-\mathrm{S} .
\end{aligned}
$$

\section{REFERENCES}

1. A. C. Thomas, T. A. du Plessis, Anne Oosterhuis and Henriëtte Oosterhuis, Polymer J., 5, 176(1973). 


\section{A. C. Thomas and T. A. DU Plessis}

2. M. H. George, "Vinyl Polymerization," Vol. 1, G. E. Ham, Ed., Marcel Dekker, New York, N. Y., 1967, Part I, p 191.

3. V. I. Vedeneyev, L. V. Gurvich, V. N. Kondratyev, V. A. Medvedev, and Ye. L. Frankevich, "Bond Energies Ionization Potentials and Electron Affinities," Edward Arnold, London,
1966, p 56.

4. Y. Yasukawa, T. Takahashi, K. Murakami, K. Araki, T. Sasuga, and H. Ohmicha, J. Polym. Sci., Part A-1, 10, 259 (1972).

5. J. W. Breitenbach, H. Goldenberg, and O. F. Olaj, Polym. Letters, 10, 911 (1972). 